\title{
Levels and Determinants of Complementary Feeding Pattern Exclusive of Minimum Meal Frequency and Dietary Diversity among Children of 6 to 23 Months in Bangladesh
}

\author{
Naznin Pervin ${ }^{1}$, Darryl Macer², Shamima P. Lasker ${ }^{3}$ \\ 1. BDS, MSc, MHE, MPH, Consultant Dental Surgeon, Salauddin Specialized Hospital Ltd, Email: \\ nazneenmowshumy@gmail.com \\ 2.MPH, Ph.D., Hon.D., AUSN President; Provost; AUSN Professor of Bioethics and Biomedicine; Director, \\ Eubios Ethics Institute (Chair),Email: provost@ausn.info \\ 3.PhD (USA), MPH (USA), EMMB (Europe), MPhil (BD), MSc (BD); Professor \& Head of Anatomy, \\ Shahbuddin Medical College, Dhaka, Bangladesh. Visiting Professor of Clinical Anatomy \& Bioethics, \\ American University of Sovereign Nation, USA. Founding Chairman \& Sectary General, Bangladesh Bioethics \\ Society, Treasurer, World Association of Medical Editors (WAME), Chairperson, Ethics \& Publication, Asian \\ Pacific Association of Medical Editors (APAME), Email: splasker04@yahoo.com Orcid ID: \\ https://orcid.org/0000-0002-3484-9526
}

\begin{abstract}
Objective: To estimate the level of complementary feeding pattern (CFP) among children aged between 6 to 23 months and to identify the determinants in individual, household and community level in Bangladesh. Methods: From secondary data of Bangladesh Demographic Health Survey (BDHS) 2011 was used in this study. A total of 2,373 children aged between 6 to 23 months were selected. To estimate the level of CFP dimension index and the "score of the index" was used as dependent variables. Statistical analyses and tests were guided by the nature of the variables. Multivariable logistic regression analyses were performed to identify the significant determinants of CFP. Results: The overall level of CFP among children aged between 6 to 23 months was low. More than $95 \%$ of the children experienced inadequate $(92.7 \%$ ) CFP level. The mean levels of CFP as well as percentages of no or inadequate $(94.1 \%)$ CFP were significantly lower among children of the youngest age group (06 months), uneducated parents, unemployed/laborer fathers, socio-economically poor families, food insecure families and rural areas. However, only few variables remained significant for adequate CFP in the multivariable logistic regression analysis. Adequate CFP was significantly lower among the children aged between 6 to 23 months (OR: $0.22,95 \%$ CI: $0.10-0.47$ ), children of illiterate fathers (OR: $0.32,95 \% \mathrm{CI}: 0.11-0.95$ ) and socio-economically middle-class families (OR: $0.28,95 \%$ CI: 0.09-0.86) as compared to their reference categories. Conclusion: Inappropriate and inadequate CFP may cause serious health hazards among children of 6 to 23 months in Bangladesh. It is ethical to take effective interventions and strategies by the government and other concerned stakeholders to improve the overall situation of CFP in Bangladesh.
\end{abstract}

Key words: CFP, children, individual, household, community, Bangladesh, Complementary Feeding, Minimum Meal Frequency, Dietary Diversity.

Introduction: Malnutrition is the largest premature mortality among young children, risk factor in the world for disability and especially in developing countries. Although the condition is entirely 
preventable. Malnutrition is a significant underlying factor in more than half of the deaths of young children in these countries $^{1}$. Recent analyses have found a decrease in child deaths under 5 years of age to 8.795 million in 2008 worldwide ${ }^{2}$. and 7.7 million in $2010^{3}$, yet malnutrition remains one of the key factors associated with global loss of life in young children $^{2,4,5}$. The objective of millennium development goals (MDGs) of United Nations (UN) focused on reducing poverty, and extreme hunger, and improving education by $2015^{6}$. One of the objectives of MDG was to decrease the prevalence of underweight children under 5 years of age (under-5 children) as the primary measure of malnutrition by $2015^{6}$.

In Ethiopia, $47 \%, 11 \%$ and $38 \%$ of children under five years of age were stunted, wasted and underweight, respectively ${ }^{7}$. An Ethiopian child is 30 times more likely to die by his or her fifth birthday than a child in Western Europe and the most common cause of child death is the interacting combination of malnutrition and infection ${ }^{8}$.

Proper feeding practices during infancy and early childhood are fundamental for normal growth, development, and survival of infants and children, particularly in developing countries 9,10,11. South Asian countries including Bangladesh reveal the highest burden of childhood undernutrition due to unimproved feeding of children that causes faltered growth and development, and illness, such as, respiratory infections, diarrheal diseases etc ${ }^{9,12}$. According to the various studies, 6-23 months of age of a child is a "critical window" for the transition of body and cognitive development 9,13. After 6 months of age, children need complementary food because breast milk or infant formula alone is no longer sufficient to maintain the child's growth ${ }^{9,13}$. At this stage, children should be fed small quantities of nutritional solid and semisolid foods in addition to breastfeeding ${ }^{13}$. The World Health Organization (WHO) and the United Nations International Children's Emergency Fund (UNICEF) have articulated a global strategy and formulated guidelines for complementary feeding of the breastfed child 14 Although appropriate complementary feeding pattern (CFP) among children aged between 6 to 23 months brings numerous health benefits ${ }^{9}$, inappropriate and inadequate introduction of CFP may increase the risk of malnutrition among under-five children 7,15,16. The levels of CFP are affected by numerous individual, household and community level factors 9,16 . The undernourished children are more likely to develop severe health hazards that impede body's metabolism and retard utilization of immunity resulting from deficiencies in immune competence ${ }^{17,18}$.

Although Bangladesh has made magnificent progress in health and human development since its independence in $19711^{19,10}$, this country shows limited success in beating the odds of child malnutrition. For instance, the prevalence 
of under-five child malnutrition in Bangladesh is nearly $40 \%$, which causes nearly $60 \%$ of under-five deaths 21 . Inappropriate feeding practice could be one of the profound causes of high under-five mortality in this country ${ }^{22}$.

Considering the limited number of studies in Bangladesh, this study aimed to estimate the levels of CFP among children of 6 to 23 months using composite dimension index and then to identify the determinants of CFP focusing on individual, household and community level factors. To our knowledge, none of the previous studies used composite dimension index to measure the levels of CFP in Bangladesh. Although dimension index is originally developed and used to calculate Human Development Index by the United Nations Development Programme (UNDP), it is also applied to address other issues ${ }^{23,24}$.

Ethical Implication: In this study secondary data was used. Hence IRB approval was not necessary. However, verbal consent was taken from BDHS. Since studies based on Dimension index to interpret CFP are still scarce, further reports to provide universally accepted cut off points to define different groups of CFP would be immensely useful for the purposes of comparison, monitoring, evaluation and advocacy.

The primary causes of malnutrition include a lack of quality food, poor infant and child feeding and care practices such as suboptimal breastfeeding, deficiency of micronutrients such as vitamin A or zinc, and recurrent attack of infections, often intensified by intestinal parasites ${ }^{25}$ In this perspective, this research is very important in this area to address the child feeding practice.

Objectives: General objectives: There is limited research on CFP and minimum meal frequency and dietary diversity among children of 6 to 23 months in Bangladesh. Therefor this study has been undertaken to estimate the levels of CFP among children of 6 to 23 months using composite dimension index and then to identify the determinants of CFP focusing on individual, household and community level factors.

Specific Objectives:

1. To find out the levels of CFP among children aged 6 to 23 months.

2. To find out the prevalence of practice of CFP based on multilevel factors.

3. To identify the determinants of CFP

Methodology: This retrospective study was performed by analysis of surveys conducted by Bangladesh Demographic and Health Survey (BDHS) in 2011 which was a nationally representative crosssectional survey, during August to November, 2015 for the master thesis of American University of Sovereign Nations (AUSN). 
Inclusion and exclusion criteria: A total of 8,761 under-five children (unweighted) born after January 2006 or later, were considered for anthropometric measurements, of which data (anthropometric and age) were completed for 7,647 children (around 88\%). Among them 2,373 children aged between 6 to 23 months were considered as final sample (figure 1). (All the under-five children outside the range of 6-23 months were excluded from the analysis. From the total of 2,405 children aged 6-23 months, 32 children were excluded due to missing information. Therefore, the final sample for analysis was 2,373 children aged 6-23 months).

Measuring levels of CFP and outcomes: To measure the level of CFP among children, 20 frequently asked questions (indicators) had been included for eligible mothers of households (Figure 2).They were: complementary food items namely, 1. plain water. 2. Noodles, bread and others made from grains. 3. Other solid, semisolid. 4. Potato, cassava and other tubers. 5. Fish or shellfish. 6. Any dark green leafy vegetable. 7. Eggs. 8. Tinned, powdered or fresh milk. 9. Any other fruits. 10. Other liquid other than juice. 11. Juice. 12. Meat. 13. Pumpkin, carrot, squash. 14. Mangoes, papayas, other vitamin A fruits. 15. Baby formula. 16. Foods made from beans, peas, lentils, nuts. 17. Fortified baby food. 18 . Yogurt 19. Liver, heart, other organs. 20. Cheese, dessert, other milk products. For each question, responses were coded binary as $1=$ yes (practice) and $0=$ no (not practice). Thereafter, the formula of "dimension index" (given below) was used in accordance with the construction method of the Human Development Index (HDI) to estimate the level of CFP 26. Firstly, Cronbach's alpha coefficient was used to evaluate the internal reliability of the 20 indicators. According to our analysis, the Cronbach's alpha estimate was 0.701, suggesting a high internal consistency. The index was then constructed using the sums of weighted binary input variables where maximum and minimum values were also chosen for underlying dimension. Performance of the dimension index was expressed into a unit-free index between 0 and $1^{26}$.The index is defined as:

$$
\begin{aligned}
& \text { Dimension Index } \\
& =\frac{\text { Actual value }- \text { Minimum value }}{\text { Maximum value }- \text { Minimum value }}
\end{aligned}
$$

The actual value here indicates the sum score of 20 binary indicators for each respondent and the maximum and minimum values were 20 and 0 , respectively. The individual score of CFP (based on dimension index) was converted into percentage by multiplying 100 . These scores were then divided into two categories. 1. Individuals with dimension score of exactly $0 \%$ belonged to the "no CFP" group. 2. Individuals with other scores ranging from $1-100 \%$ belonged to the "CFP" group (20). The CFP scores were 


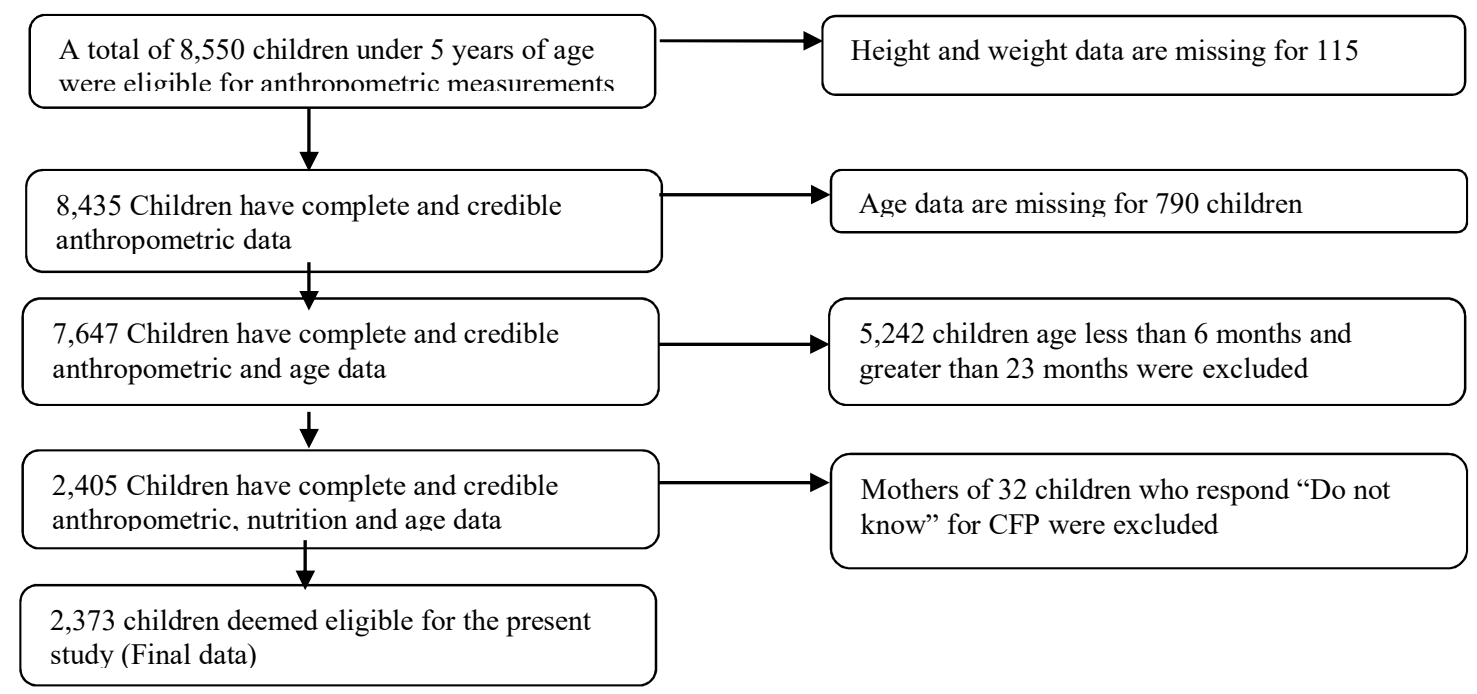

Figure 1: Sample size selection

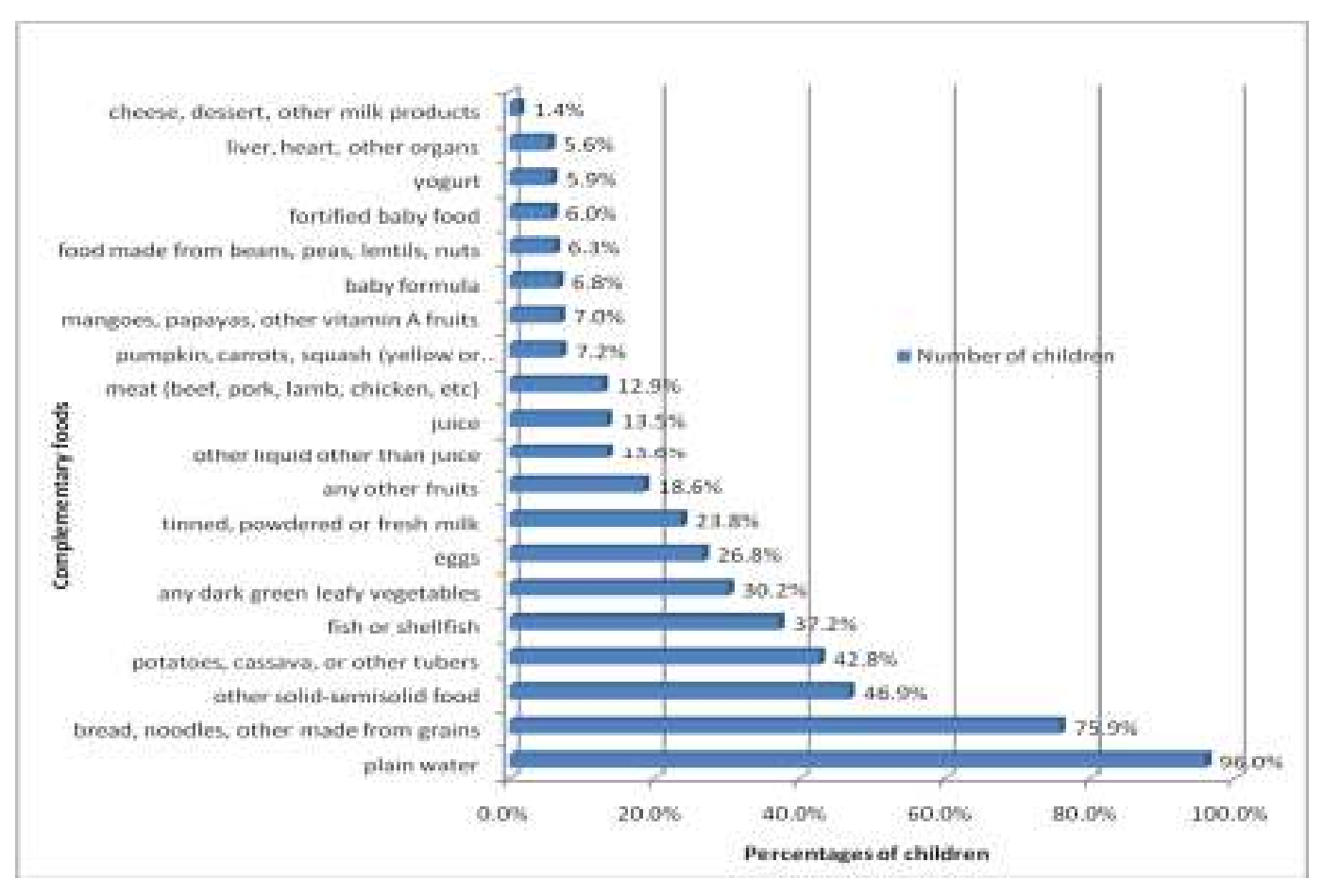

Figure 2: Percentage of complementary foods received by children (BDHS 2011) 
again divided into three categories: no CFP

(0 \%), inadequate CFP (1-49\%) and adequate CFP ( $\geq 50.0 \%$ ). Both variables with two and three categories were used as dependent variables in multivariable analyses.

Covariates: Covariates were classified into three level characteristics: individual, household, and community characteristics. Individual level characteristics were: age of child (6-11 months, 12-17 months, 18-23 months); sex of child (male, female); mother's education (illiterate, literate); father's education (illiterate, literate); father's employment status (currently unemployed composed of unemployed persons and students, laborers composed of farmer, agricultural worker, fisherman and rickshaw etc.; service holders composed of doctor, lawyer, accountant, teacher and so on; businessman). Household socioeconomic status based on wealth index (poor, middle, rich), mass media exposure through television, radio and newspaper/magazine (yes: all medias exposed to at least once a week, no); food insecurity (yes, no) were considered as the household level characteristics. The wealth index was constructed using household asset data via principal components analysis ${ }^{27}$.

Household socio-economic status was considered as the household-level characteristics. Household socioeconomic status, namely the wealth index was constructed from data on household assets, including ownership of durable goods factors with CFP. Statistical significance (analyses were carried out using SPSS software (version 20.0). such as televisions and bicycles) and dwelling characteristics (such as source of drinking water, sanitation facilities, and construction materials). Principal components analyses were used to assign individual household wealth scores. These weighted values were then summed and rescaled to range from $0-1$, and each household was assigned into quintiles: the first quintile: poorest, the second quintile: poorer, the third quintile: middle class, the fourth quintile: richer and the fifth quintile: richest ${ }^{27}$. Five household food security indicators were selected using the Household Food Insecurity Access Scale. Community level characteristics were represented by the place of residence (urban, rural) and region of residence (south, south-east, central, mid-west, northwest, and east).

Statistical analysis: The continuous score of CFP based on dimension index were tested using ANOVA-test and t-test. These tests tested the differences of CFP among various categories of each independent variable. Contingency analysis was used to test the bivariable associations between the CFP (with three categories) and selected factors by applying the Chi-square $\left(\chi^{2}\right)$ test. Multivariable binary/multinomial logistic regressions (binary for CFP scores with two categories and multinomial for CFP scores with three categories) were 
used to examine the associations of selected was accepted at $\mathrm{P}<0.05$. Statistical

Study limitations: This study is not free from limitations. Due to unavailability of recent data, ${ }^{27}$. Data was used in this study that does not present the current nutritional status. The cross-sectional nature of the study limits us to assess the cause and effect relationships between selected factors and CFP. Most of the food items were given to the children in last 24-hours preceding the survey time, however, the children could occasionally receive some other foods but simply did not the previous day. All food items were treated equally may limit this study. Another limitation could be information bias, which may result from collecting information of self-reporting age, education, occupation, household assets as well as nutritional indicators.

Result: The mean level of CFP was 24.2, which was significantly lower among the children aged 6-11 months (19.1\%), illiterate mother (18.8\%), illiterate father $(19.8 \%)$ and also among children of currently unemployed families $(22.6 \%)$ (Table 4.1). Children belonging to the poorest socio-economic group (19.6\%), no exposure to television (20.7\%) and newspapers $(22.9 \%)$, food insecurity $(22.2 \%)$ and rural area $(20.70 \%)$ also revealed significantly lower scores of CFP. Moreover, the mean level of CFP varied significantly among various geographical regions with the lowest level in southeastern region.

The overall level of CFP experienced by children aged between 6 to 23 months in Bangladesh could be described as a catastrophe. Poor level of CFP was measured significantly using multilevel factors, such as, age, parental education, father's employment status, socioeconomic status, mass media exposure, food insecurity, pace of residence and region of residence.

Interclass variations of the percentages, based on multilevel factors (e. g. individual, household and community levels), of the children among the various level of CFP (e.g. no CFP, inadequate CFP and adequate CFP) were observed using Chi-square test. According to the categories of dimension index, more than $90 \%$ children received inadequate complementary food. Children age, mother's education, father's education, father's employment status, socioeconomic status, mass media exposures (television and newspaper/magazine), food insecurity and place of residence were significantly associated with CFP categories (Table 4.2). For instance, the percentage of adequate CFP was significantly lower among younger group of children (2.5\%), among children of illiterate mother $(1.8 \%)$, illiterate father $(1.0 \%)$. Similarly, the percentage of adequate CFP was significantly lower among the children of those families, who belonged to the groups of socioeconomically poor $(1.6 \%)$, no mass media 
Bangladesh Journal of Bioethics 2018; 9 (3): 28-44

Table 4.1 Mean level of complementary feeding practice

\begin{tabular}{|c|c|c|c|}
\hline Variables & Mean ( \pm SD) (\%) & Standard Error (SE) (\%) & P values \\
\hline \multicolumn{4}{|l|}{ Children age (months) } \\
\hline $6-11$ & $19.1( \pm 11.7)$ & 0.40 & \\
\hline $12-17$ & $26.2( \pm 11.8)$ & 0.42 & $<0.001^{\mathrm{a}}$ \\
\hline $18-23$ & $28.0( \pm 12.2)$ & 0.45 & \\
\hline \multicolumn{4}{|l|}{ Sex of child } \\
\hline Male & $23.9( \pm 12.4)$ & 0.36 & $0.332^{\mathrm{b}}$ \\
\hline Female & $24.5( \pm 12.5)$ & 0.36 & \\
\hline \multicolumn{4}{|l|}{ Mother's education } \\
\hline Illiterate & $18.8( \pm 9.97)$ & 0.51 & $<0.001^{\mathrm{b}}$ \\
\hline Literate & $25.2( \pm 12.7)$ & 0.28 & \\
\hline \multicolumn{4}{|l|}{ Father's education } \\
\hline Illiterate & $19.8( \pm 10.7)$ & 0.43 & $<0.001^{\mathrm{b}}$ \\
\hline Literate & $25.7( \pm 12.7)$ & 0.30 & \\
\hline \multicolumn{4}{|l|}{ Father's employment status } \\
\hline Currently unemployed & $22.6( \pm 13.9)$ & 1.91 & \\
\hline Labours & $23.3( \pm 11.8)$ & 0.29 & $<0.001^{\mathrm{a}}$ \\
\hline Service holders & $26.1( \pm 13.2)$ & 0.59 & \\
\hline Businessmen & $28.8( \pm 14.5)$ & 1.20 & \\
\hline \multicolumn{4}{|l|}{ Socioeconomic status } \\
\hline Poor & $19.6( \pm 10.6)$ & 0.47 & $<0.001^{\mathrm{a}}$ \\
\hline Middle & $21.4( \pm 11.1)$ & 0.52 & \\
\hline Rich & $26.7( \pm 12.8)$ & 0.34 & \\
\hline \multicolumn{4}{|l|}{ Watch television weekly } \\
\hline No & $20.7( \pm 11.1)$ & 0.36 & $<0.001^{\mathrm{b}}$ \\
\hline Yes & $26.5( \pm 12.8)$ & 0.34 & \\
\hline \multicolumn{4}{|l|}{ Listen to radio weekly } \\
\hline No & $24.1( \pm 12.5)$ & 0.27 & 0.179 \\
\hline Yes & $25.3( \pm 12.8)$ & 0.89 & \\
\hline \multicolumn{4}{|c|}{ Read newspapers/magazine weekly } \\
\hline No & $22.9( \pm 11.8)$ & 0.27 & $<0.001^{\mathrm{b}}$ \\
\hline Yes & $30.4( \pm 13.7)$ & 0.68 & \\
\hline \multicolumn{4}{|l|}{ Food insecurity } \\
\hline No & $25.3( \pm 12.9)$ & 0.33 & $<0.001^{\mathrm{b}}$ \\
\hline Yes & $22.2( \pm 11.3)$ & 0.40 & \\
\hline \multicolumn{4}{|l|}{ Place of residence } \\
\hline Urban & $27.4( \pm 13.4)$ & 0.49 & $<0.001^{\mathrm{b}}$ \\
\hline Rural & $22.8( \pm 11.8)$ & 0.29 & \\
\hline \multicolumn{4}{|l|}{ Region of residence } \\
\hline Southern & $23.7( \pm 12.5)$ & 0.76 & \\
\hline Southeastern & $22.3( \pm 12.9)$ & 0.58 & \\
\hline Central & $23.6( \pm 12.7)$ & 0.66 & \\
\hline Western & $28.8( \pm 11.4)$ & 0.69 & $<0.001^{\mathrm{a}}$ \\
\hline Mid-western & $26.2( \pm 11.8)$ & 0.67 & \\
\hline Northwestern & $25.9( \pm 11.2)$ & 0.65 & \\
\hline Eastern & $21.1( \pm 12.6)$ & 0.67 & \\
\hline Total & $24.2( \pm 12.5)$ & 0.26 & \\
\hline
\end{tabular}

SD, Standard deviation; SE, Standard error; $\mathrm{a}=$ ANOVA test $\mathrm{b}=\mathrm{T}$-test 
exposure $(2.0 \%$ for television and $3.0 \%$ newspaper/magazine), food insecurity $(2.6 \%)$ and rural area $(3.0 \%)$. In contrast, the percentage of inadequate CFP was significantly higher among younger the children aged 12-17 months (94.1\%), among children of illiterate mother $(95.3 \%)$, illiterate father $(95.9 \%)$, the children of those families, who belonged to the groups of socio-economically poor (95.4\%), no mass media exposure $(94.6 \%$ for television and $94.0 \%$ newspaper/magazine), food insecurity $(94.7 \%)$ and rural area (93.7\%). Only 4.4\% children were found to receive adequate CFP. All multilevel factors other than sex of child, listening to radio and region of residence were significantly associated with CFP.

\section{Multivariable association of CFP with multilevel independent variables: Multivariable logistic regression (binary/multinomial) analysis have been performed to identify the determinants of CFP or to observe the effects of several socio-demographic factors based on individual, household and community level factors. The results of binary logistic regression were presented first under the dichotomous dependent variable "any CFP".}

According to these results (Table 4.3.), children aged between 6 to 23 of age were less likely to receive any CFP (OR: 0.55 , 95\% CI: 0.32-0.96) as compared to the group of 18-23 months. In contrast, children of 12-17 months of age were more likely to receive any CFP (OR: 2.63, 95\% CI: 1.14-6.07). Other variables were not significantly associated with the dependent variable "any feeding practice".

According to the results of multinomial logistic regression analysis (presented under the categories of inadequate and adequate take 'no CFP' as a reference in Table 4.3), children of illiterate fathers had significantly less likelihood of having adequate CFP (OR: 0.32, 95\% CI: 0.11$0.95)$. Children from the socioeconomically middle class families were less likely to receive adequate $\mathrm{CFP}$ (OR: $0.28,95 \% \mathrm{CI}$ : 0.09-0.86) as compared to rich children. Children of families with no exposure to newspaper/magazine also revealed significantly less likelihood of receiving adequate CFP (OR: 0.38, 95\% CI: 0.160.92) than reference category. Place of residence had somewhat significant effect $(\mathrm{P}=0.09)$ on adequate CFP.

Most of the socio-demographic variables were not significantly associated with CFP. Some factors, such as, children age, father's education, socioeconomic status and frequency of reading newspaper/magazine had significant effects on adequate CFP.

Table 4.4 highlights the association between child underweight and CFP. CFP was significantly $(p=0.005)$ associated with underweight. More than $30 \%$ children received inadequate complementary foods were underweight. Other factors, such as, children age, mother's education, father's education, father's occupational status, 
socio-economic status, watch television weekly, read newspapers/magazine weekly, food insecurity, place of residence and region of residence were significantly associated with child underweight.

Binary logistic regression analysis showed that CFP had significant effect on child underweight. Children who were fed inadequate food had more chance to be underweight than those who did not receive any complementary food. Other factors, such as, children age, socio-economic status, watch television weekly, read newspapers/magazine weekly, food insecurity, place of residence and region of residence had significant impact on child underweight.

Discussion: The study reveals a low level of CFP (composed of no CFP or low CFP) among children aged between 6 to 23 months in Bangladesh. The higher prevalence of under-nutritious complementary foods during the early mentioned "critical window" period of growth for children. Our findings are consistent with the findings of a study in Bangladesh 28. and other South Asian countries such as India, Pakistan, Sri Lanka and Nepal 9,29,30. Lack of knowledge and awareness regarding appropriate CFP may influence the poor nutritional supplements among children ${ }^{31}$. According to my knowledge, no previous studies have addressed the level of CFP through dimension index based on 20 complementary food items.

We found significant interclass variations of CFP for different individual, household and community level variables. For instance, receiving complementary foods were significantly lower among children of the younger age group (6-11 months) than among those in the older age group (18-23 months). Several studies reported that percentages of infants receiving complementary foods increases with age but did not show any significant variations 32,33,34 . CFP was also found significantly lower among children of illiterate parents, children of fathers who were labourers, socioeconomically poor families, children of families never exposed to mass media, food insecure families and rural settlement. These findings were consistent with another study conducted in Nepal ${ }^{34}$.

The United Nations Children's Fund (UNICEF) reported that in Bangladesh over 33 million children under 18 years of old, which accounts for around $56 \%$ of the child population, are currently living below the international poverty line and around 57\% are deprived of adequate nutrition ${ }^{27}$. Bangladesh is one of the South Asian countries where female children experience higher mortality than males ${ }^{35}$. In this country, more attention is paid to male children in intra-family food distribution and healthcare. Such kinds of discrimination against female children can aggravate the situation of under-nutrition and other health 
Bangladesh Journal of Bioethics 2018; 9 (3): 28-44

Table 4.2 Associations between multilevel factors and complementary feeding pattern

\begin{tabular}{|c|c|c|c|c|}
\hline \multirow{2}{*}{ Variables } & \multicolumn{3}{|c|}{ Complementary feeding pattern } & \multirow{2}{*}{$P$ values } \\
\hline & No & Inadequate CFP & Adequate CFP & \\
\hline \multicolumn{5}{|l|}{ Children age (months) } \\
\hline $6-11$ & $41(4.8 \%)$ & $791(92.7 \%)$ & $21(2.5 \%)$ & $<0.001$ \\
\hline $12-17$ & $8(1.0 \%)$ & $753(94.1 \%)$ & $39(4.9 \%)$ & \\
\hline $18-23$ & $19(2.6 \%)$ & $656(91.1 \%)$ & $45(6.2 \%)$ & \\
\hline \multicolumn{5}{|l|}{ Sex of child } \\
\hline Male & $36(3.0 \%)$ & $1109(92.5 \%)$ & $54(4.5 \%)$ & 0.903 \\
\hline Female & $32(2.7 \%)$ & $1091(92.9 \%)$ & $51(4.3 \%)$ & \\
\hline \multicolumn{5}{|l|}{ Mother's education } \\
\hline Illiterate & $11(2.9 \%)$ & $362(95.3 \%)$ & $7(1.8 \%)$ & 0.028 \\
\hline Literate & $57(2.9 \%)$ & $1838(92.2 \%)$ & $98(4.9 \%)$ & \\
\hline \multicolumn{5}{|l|}{ Father's education } \\
\hline Illiterate & $19(3.1 \%)$ & $580(95.9 \%)$ & $6(1.0 \%)$ & $<0.001$ \\
\hline Literate & $49(2.8 \%)$ & $1620(91.6 \%)$ & $99(5.6 \%)$ & \\
\hline \multicolumn{5}{|l|}{ Father's employment status } \\
\hline Currently unemployed & $3(5.7 \%)$ & $48(90.6 \%)$ & $2(3.8 \%)$ & \\
\hline Labours & $45(2.7 \%)$ & $1568(94.2 \%)$ & $52(3.1 \%)$ & $<0.001$ \\
\hline Service holders & $17(3.3 \%)$ & $457(89.8 \%)$ & $35(6.9 \%)$ & \\
\hline Businessmen & $3(2.1 \%)$ & $127(87.0 \%)$ & $16(11.0 \%)$ & \\
\hline \multicolumn{5}{|l|}{ Socioeconomic status } \\
\hline Poor & $15(3.0 \%)$ & $474(95.4 \%)$ & $8(1.6 \%)$ & $<0.001$ \\
\hline Middle & $17(3.7 \%)$ & $433(95.0 \%)$ & $6(1.3 \%)$ & \\
\hline Rich & $36(2.5 \%)$ & $1293(91.1 \%)$ & $91(6.4 \%)$ & \\
\hline \multicolumn{5}{|l|}{ Watch Television weekly } \\
\hline No & $31(3.3 \%)$ & $880(94.6 \%)$ & $19(2.0 \%)$ & $<0.001$ \\
\hline Yes & $37(2.6 \%)$ & $1320(91.5 \%)$ & $86(6.0 \%)$ & \\
\hline \multicolumn{5}{|l|}{ Listen radio weekly } \\
\hline No & $61(2.8 \%)$ & $2013(92.9 \%)$ & $94(4.3 \%)$ & 0.691 \\
\hline Yes & $7(3.4 \%)$ & $187(91.2 \%)$ & $11(5.4 \%)$ & \\
\hline \multicolumn{5}{|c|}{ Read newspapers/magazine weekly } \\
\hline No & $59(3.0 \%)$ & $1850(94.0 \%)$ & $60(3.0 \%)$ & $<0.001$ \\
\hline Yes & $9(2.2 \%)$ & $350(86.6 \%)$ & $45(11.1 \%)$ & \\
\hline \multicolumn{5}{|l|}{ Food insecurity } \\
\hline No & $45(2.9 \%)$ & $1421(91.7 \%)$ & $84(5.4 \%)$ & 0.005 \\
\hline Yes & $23(2.8 \%)$ & $779(94.7 \%)$ & $21(2.6 \%)$ & \\
\hline \multicolumn{5}{|l|}{ Place of residence } \\
\hline Urban & $14(1.9 \%)$ & $660(90.5 \%)$ & $55(7.5 \%)$ & $<0.001$ \\
\hline Rural & $54(3.3 \%)$ & $1540(93.7 \%)$ & $50(3.0 \%)$ & \\
\hline \multicolumn{5}{|l|}{ Region of residence } \\
\hline Southern & $4(1.5 \%)$ & $252(94.7 \%)$ & $10(3.8 \%)$ & \\
\hline Southeastern & $22(4.4 \%)$ & $451(90.4 \%)$ & $26(5.2 \%)$ & \\
\hline Central & $7(1.9 \%)$ & $354(93.7 \%)$ & $17(4.5 \%)$ & 0.398 \\
\hline Western & $6(2.2 \%)$ & $248(92.2 \%)$ & $15(5.6 \%)$ & \\
\hline Mid-western & $8(2.6 \%)$ & $285(92.5 \%)$ & $15(4.9 \%)$ & \\
\hline Northwestern & $9(3.0 \%)$ & $278(93.0 \%)$ & $12(4.0 \%)$ & \\
\hline Eastern & $12(3.4 \%)$ & $332(93.8 \%)$ & $10(2.8 \%)$ & \\
\hline Total & $68(2.9 \%)$ & $2200(92.7 \%)$ & $105(4.4 \%)$ & \\
\hline
\end{tabular}


Bangladesh Journal of Bioethics 2018; 9 (3): 28-44

Table 4.3 Results of multivariable logistic regression analysis

\begin{tabular}{|c|c|c|c|c|c|c|}
\hline \multirow{3}{*}{ Variables } & \multicolumn{6}{|c|}{ Complementary feeding pattern } \\
\hline & \multicolumn{2}{|c|}{ Any CFP (yes/no) } & \multicolumn{2}{|c|}{ Inadequate CFP } & \multicolumn{2}{|c|}{ Adequate CFP } \\
\hline & $\begin{array}{c}\text { Adjusted } \\
\text { OR }(95 \% \text { CI })\end{array}$ & P values & $\begin{array}{c}\text { Adjusted } \\
\text { OR }(95 \% \text { CI })\end{array}$ & $\begin{array}{c}\mathbf{P} \\
\text { values }\end{array}$ & $\begin{array}{c}\text { Adjusted } \\
\text { OR }(95 \% \text { CI })\end{array}$ & $P$ values \\
\hline \multicolumn{7}{|l|}{ Children age (months) } \\
\hline $6-11$ & $0.55(0.32-0.96)$ & $<0.001$ & $0.57(0.33-1.00)$ & 0.050 & $0.22(0.10-0.47)$ & $<0.001$ \\
\hline $12-17$ & $2.63(1.14-6.07)$ & 0.037 & $2.68(1.16-6.19)$ & 0.021 & $1.84(0.72-4.71)$ & 0.206 \\
\hline $18-23$ (ref.) & 1.00 & & 1.00 & & 1.00 & \\
\hline \multicolumn{7}{|l|}{ Sex of child } \\
\hline Male & $0.92(0.56-1.49)$ & 0.725 & $0.91(0.56-1.50)$ & 0.719 & $1.01(0.54-1.89)$ & 0.978 \\
\hline Female (ref.) & 1.00 & & 1.00 & & 1.00 & \\
\hline \multicolumn{7}{|l|}{ Mother's education } \\
\hline Illiterate & $1.11(0.52-2.37)$ & 0.779 & $1.11(0.52-2.35)$ & 0.792 & $1.48(0.46-4.69)$ & 0.509 \\
\hline Literate (ref.) & 1.00 & & 1.00 & & 1.00 & \\
\hline \multicolumn{7}{|l|}{ Father's education } \\
\hline Illiterate & $1.01(0.54-1.89)$ & 0.981 & $1.03(0.55-1.92)$ & 0.934 & $0.32(0.11-0.95)$ & 0.040 \\
\hline Literate (ref.) & 1.00 & & 1.00 & & 1.00 & \\
\hline \multicolumn{7}{|l|}{ Father's employment status } \\
\hline Currently unemployed & $0.42(0.08-2.25)$ & 0.313 & $0.44(0.08-2.36)$ & 0.341 & $0.23(0.02-2.12)$ & 0.193 \\
\hline Labours & $0.94(0.28-3.20)$ & 0.918 & $0.98(0.29-3.35)$ & 0.976 & $0.49(0.13-1.89)$ & 0.297 \\
\hline Service holders & $0.68(0.19-2.40)$ & 0.551 & $0.70(0.20-2.48)$ & 0.584 & $0.50(0.13-2.01)$ & 0.330 \\
\hline Businessman (ref.) & 1.00 & & 1.00 & & 1.00 & \\
\hline \multicolumn{7}{|l|}{ Socioeconomic status } \\
\hline Poor & $0.85(0.39-1.84)$ & 0.539 & $0.86(0.40-1.86)$ & 0.704 & $0.55(0.18-1.70)$ & 0.299 \\
\hline Middle & $0.69(0.35-1.34)$ & 0.687 & $0.70(0.36-1.37)$ & 0.297 & $0.28(0.09-0.86)$ & 0.025 \\
\hline Rich (ref.) & 1.00 & & 1.00 & & 1.00 & \\
\hline \multicolumn{7}{|l|}{ Watch Television weekly } \\
\hline No & $0.89(0.51-1.57)$ & 0.695 & $0.90(0.51-1.58)$ & 0.712 & $0.68(0.31-1.49)$ & 0.336 \\
\hline Yes (ref.) & 1.00 & & 1.00 & & 1.00 & \\
\hline \multicolumn{7}{|l|}{ Listen radio weekly } \\
\hline No & $1.24(0.55-2.81)$ & 0.607 & $1.24(0.55-2.81)$ & 0.608 & $1.21(0.42-3.44)$ & 0.722 \\
\hline Yes (ref.) & 1.00 & & 1.00 & & 1.00 & \\
\hline \multicolumn{7}{|c|}{ Read newspapers/magazine weekly } \\
\hline No & $0.82(0.38-1.77)$ & 0.602 & $0.86(0.40-1.85)$ & 0.702 & $0.38(0.16-0.92)$ & 0.032 \\
\hline Yes (ref.) & 1.00 & & 1.00 & & 1.00 & \\
\hline \multicolumn{7}{|l|}{ Food insecurity } \\
\hline No & $0.83(0.47-1.46)$ & 0.526 & $0.83(0.47-1.46)$ & 0.518 & $0.90(0.42-1.95)$ & 0.796 \\
\hline Yes (ref.) & 1.00 & & 1.00 & & 1.00 & \\
\hline \multicolumn{7}{|l|}{ Place of residence } \\
\hline Urban & $1.43(0.75-2.70)$ & 0.275 & $1.40(0.74-2.65)$ & 0.300 & $1.93(0.90-4.13)$ & 0.090 \\
\hline Rural (ref.) & 1.00 & & 1.00 & & 1.00 & \\
\hline \multicolumn{7}{|l|}{ Region of residence } \\
\hline Southern & $2.40(0.75-7.70)$ & 0.276 & $2.40(0.75-7.68)$ & 0.141 & $2.84(0.65-12.38)$ & 0.164 \\
\hline Southeastern & $0.72(0.34-1.49)$ & 0.140 & $0.71(0.34-1.47)$ & 0.357 & $1.26(0.44-3.58)$ & 0.663 \\
\hline Central & $1.67(0.64-4.34)$ & 0.380 & $1.65(0.65-4.30)$ & 0.304 & $2.42(0.69-8.45)$ & 0.165 \\
\hline Western & $1.34(0.49-3.73)$ & 0.294 & $1.32(0.48-3.66)$ & 0.592 & $2.44(0.66-9.01)$ & 0.182 \\
\hline Mid-western & $1.19(0.47-3.01)$ & 0.570 & $1.17(0.47-2.97)$ & 0.735 & $2.03(0.59-6.99)$ & 0.263 \\
\hline Northwestern & $1.19(0.48-2.92)$ & 0.711 & $1.17(0.48-2.88)$ & 0.733 & $2.04(0.58-7.13)$ & 0.263 \\
\hline Eastern (ref.) & 1.00 & & 1.00 & & 1.00 & \\
\hline
\end{tabular}

CI, $95 \%$ confidence interval 
Bangladesh Journal of Bioethics 2018; 9 (3): 28-44

Table 4.4 Association between underweight and child feeding practice

\begin{tabular}{|c|c|c|c|c|c|c|c|c|}
\hline \multirow[t]{3}{*}{ Variables } & \multicolumn{2}{|c|}{ Under Weight (n=2227) } & \multicolumn{6}{|c|}{ Underweight (No/Yes) (Binary logistic regression results) } \\
\hline & \multirow[t]{2}{*}{ Prevalence } & \multirow{2}{*}{$\begin{array}{l}\text { P values (Chi } \\
\text { square) }\end{array}$} & \multirow[b]{2}{*}{ B } & \multirow[b]{2}{*}{ S.E. } & \multirow[b]{2}{*}{$P$ values } & \multirow[b]{2}{*}{ ORs } & \multicolumn{2}{|c|}{$95.0 \%$ C.I. } \\
\hline & & & & & & & Lower & Upper \\
\hline \multicolumn{9}{|l|}{ Child feeding pattern } \\
\hline No (ref) & $13(20.6 \%)$ & & & & & 1.00 & & \\
\hline Inadequate & $675(32.6 \%)$ & 0.005 & 0.60 & 0.33 & 0.041 & 1.82 & 0.95 & 3.48 \\
\hline Adequate & $18(19.6 \%)$ & & 0.23 & 0.49 & 0.585 & 1.26 & 0.54 & 2.93 \\
\hline \multicolumn{9}{|l|}{ Children age (months) } \\
\hline $6-11$ (ref) & $197(24.6 \%)$ & & & & & 1.00 & & \\
\hline $12-17$ & $246(32.5 \%)$ & $<0.001$ & 0.50 & 0.11 & $<0.001$ & 1.65 & 1.31 & 2.09 \\
\hline $18-23$ & $263(39.4 \%)$ & & 0.76 & 0.12 & $<0.001$ & 2.13 & 1.68 & 2.70 \\
\hline \multicolumn{9}{|l|}{ Sex of child } \\
\hline Male (ref) & $357(31.8 \%)$ & 0.905 & & & & 1.00 & & \\
\hline Female & $349(31.6 \%)$ & & -0.01 & 0.09 & 0.900 & 0.98 & 0.81 & 1.19 \\
\hline \multicolumn{9}{|l|}{ Mother's education } \\
\hline Illiterate (ref) & $160(45.8 \%)$ & $<0.001$ & & & & 1.00 & & \\
\hline Literate & $546(29.1 \%)$ & & -0.08 & 0.14 & 0.573 & 0.92 & 0.69 & 1.22 \\
\hline \multicolumn{9}{|l|}{ Father's education } \\
\hline Illiterate (ref) & $239(42.4 \%)$ & $<0.001$ & & & & 1.00 & & \\
\hline Literate & $467(28.1 \%)$ & & -0.10 & 0.12 & 0.392 & 0.90 & 0.70 & 1.14 \\
\hline \multicolumn{9}{|l|}{ Father's employment status } \\
\hline Currently unemployed (ref) & $11(22.9 \%)$ & & & & 0.444 & 1.00 & & \\
\hline Labours & $546(34.9 \%)$ & $<0.001$ & 0.53 & 0.36 & 0.142 & 1.70 & 0.83 & 3.47 \\
\hline Service holders & $119(24.9 \%)$ & & 0.43 & 0.37 & 0.250 & 1.53 & 0.73 & 3.20 \\
\hline Businessmen & $30(21.9 \%)$ & & 0.43 & 0.41 & 0.296 & 1.54 & 0.68 & 3.50 \\
\hline \multicolumn{9}{|l|}{ Socioeconomic status } \\
\hline Poor (ref) & $225(49.1 \%)$ & & & & & 1.00 & & \\
\hline Middle & $167(38.7 \%)$ & $<0.001$ & -0.32 & 0.14 & 0.023 & 0.72 & 0.54 & 0.95 \\
\hline Rich & $314(23.5 \%)$ & & -0.76 & 0.14 & $<0.001$ & 0.46 & 0.35 & 0.61 \\
\hline \multicolumn{9}{|l|}{ Watch Television weekly } \\
\hline No (ref) & $365(41.9 \%)$ & $<0.001$ & & & & 1.00 & & \\
\hline Yes & $341(25.1 \%)$ & & -0.28 & 0.11 & 0.010 & 0.75 & 0.60 & 0.93 \\
\hline \multicolumn{9}{|l|}{ Listen radio weekly } \\
\hline No (ref) & $649(31.9 \%)$ & 0.498 & & & & 1.00 & & \\
\hline Yes & $57(29.5 \%)$ & & -0.01 & 0.17 & 0.975 & 0.99 & 0.70 & 1.40 \\
\hline Read newspapers/magazine wee & & & & & & & & \\
\hline No (ref) & $632(34.1 \%)$ & $<0.001$ & & & & 1.00 & & \\
\hline Yes & $74(19.7 \%)$ & & -0.25 & 0.15 & 0.090 & 0.77 & 0.57 & 1.04 \\
\hline Food insecurity & & & & & & & & \\
\hline No (ref) & $394(27.0 \%)$ & $<0.001$ & & & & 1.00 & & \\
\hline Yes & $312(40.5 \%)$ & & 0.28 & 0.10 & 0.007 & 1.33 & 1.08 & 1.64 \\
\hline Place of residence & & & & & & & & \\
\hline Urban (ref) & $167(24.1 \%)$ & $<0.001$ & & & & 1.00 & & \\
\hline Rural & $539(35.1 \%)$ & & 0.14 & 0.11 & 0.229 & 1.15 & 0.91 & 1.44 \\
\hline Region of residence & & & & & & & & \\
\hline Southern (ref) & $84(33.3 \%)$ & & & & & 1.00 & & \\
\hline Southeastern & $152(32.8 \%)$ & & 0.09 & 0.17 & 0.580 & 1.10 & 0.78 & 1.55 \\
\hline Central & $110(30.7 \%)$ & & -0.11 & 0.18 & 0.534 & 0.89 & 0.61 & 1.28 \\
\hline Western & $57(22.1 \%)$ & $<0.001$ & -0.46 & 0.21 & 0.027 & 0.62 & 0.41 & 0.94 \\
\hline Mid-western & $80(28.1 \%)$ & & -0.26 & 0.19 & 0.184 & 0.76 & 0.52 & 1.13 \\
\hline Northwestern & $85(30.6 \%)$ & & -0.28 & 0.19 & 0.151 & 0.75 & 0.51 & 1.10 \\
\hline Eastern & $138(41.6 \%)$ & & 0.35 & 0.18 & 0.061 & 1.42 & 0.98 & 2.05 \\
\hline
\end{tabular}


hazards among female children compared to male

36. Regional variation also has been observed in terms of CFP. Variations in CFP may conceal important intra-regional differences due to diverse cultural norms and needs more investigation.

Conclusion: The overall level of CFP among children is still low in Bangladesh and needs further improvement. The levels of CFP are found to be strongly associated with several individual, household and community factors. Some of these factors namely children's age, father's education, socioeconomic status, mass media exposure and place of residence are justified to be considered while developing strategies or interventions to address the issue of child CFP in Bangladesh. More studies are needed to assess the level of CFP in Bangladesh.

Recommendations: Although numerous policies and strategies have been issued in Bangladesh to improve the IYCFP, some challenges such as insufficient resources and lack of coordination among stakeholders are impeding their implementation and enforcement.

1. Strengthening of the existing strategies such as eradication of poverty through marginalized and vulnerable group development, empowering women to practice decision making autonomy and minimizing rural urban differential through planning and providing modern facilities are urgently necessary to improve the situation of CFP in Bangladesh.

2. Proper CFP can also be ensured by undertaking social safety net program and community-based nutritional interventions, for example, food for education, food for work for slum dwellers and so on ${ }^{28}$.

3. The feeding practice of home-based foods with various textures should be encouraged ${ }^{37}$.

4. Health promotion program through crosscollaboration among various organizations are needed to ensure proper CFP.

5. Behavioral change communication through nutritional education, particularly in slum and rural areas, which support and educate mothers, need to be developed for improving appropriate feeding practice to children 38,39. In addition, more efforts should be given to review existing nutritional interventions that target the IYCFP in Bangladesh.

6. Longitudinal studies are recommended to determine the cause-effect relationships between plausible factors and CFP in Bangladesh. 


\section{References}

1. Muller O, Krawinkel M. Malnutrition and health in developing countries. Can Med Assoc J 2005; 173:279-286.

2. Black RE, Cousens S, Johnson HL, Li JE, Rudan I, Bassani DG et al. Global, regional, and national causes of child mortality in 2008: a systematic analysis. Lancet 2008; 375: 1969-1987.

3. Radwan H. Patterns and determinants of breastfeeding and complementary feeding practices of Emirati Mothers in the United Arab Emirates. BMC Public Health 2013, 13:171.

4. Jones G, Steketee RW, Black RE, Bhutta ZA, Morris SS. How many child deaths can we prevent this year? Lancet 2003; 362: 6571.

5. UNICEF. The State of the World's Children: Special Edition: Celebrating 20 Years of the Convention on the Rights of the Child. 2009.

6. United Nation. Millennium development goals. 2000 . http://www.un.org/millenniumgoals/ (Accessed on 1 July 2019)

7. Central Statistical Agency. Ethiopia Demographic and health survey. Addis Ababa Ethiopia, 2011.

8. Joan J, Mesfin BH. Report on review of Incorporation of Essential Nutrition Actions into Public Health Programs in Ethiopia; Food and Nutrition Technical Assistance (FANTA) Project, Academy for Educational Development (AED) Ethiopia: Addis Ababa; 2008

9. Senarath U, Dibley MJ. Complementary feeding practices in South Asia: analyses of recent national survey data by the South Asia Infant Feeding Research Network. Maternal and Child Nutrition.2012; 8(1): 5-10.
10. Saha KK, Frongillo EA, Alam DS, Arifeen SE, Persson LÅ, Rasmussen KM. Appropriate infant feeding practices result in better growth of infants and young children in rural Bangladesh. Am J Clin Nutr 2008; 87: 1852-9.

11. Srivastava N, Sandhu A. Index for measuring child feeding practices. Indian J Pediatr 2007; 74 (4): 363-368.

12. Menon $P$. The crisis of poor complementary feeding in South Asia: where next? Maternal and Child Nutrition. 2012; 8(1): 1-4.

13. World Health Organization (WHO). Indicators for Assessing Infant and Young Child Feeding Practices: Conclusions of a Consensus Meeting Held 6-8 November 2007 in Washington D.C., USA. Geneva, Switzerland: WHO; 2008.

14. Pan American Health Organization. Guiding principles for complementary feeding of the breastfed child. Washington, DC: Pan American Health Organization, World Health Organization, Division of Health Promotion and Protection, Food and Nutrition Program, 2001.

15. Inayati DA, Scherbaum V, Purwestri RC, Hormann E, Wirawan NN, Suryantan J, et al. Infant feeding practices among mildly wasted children: a retrospective study on Nias Island, Indonesia. International Breastfeeding Journal. 2012; 7:3.

16. Kumar D, Goel NK, Mittal PC, Misra P. Influence of infant-feeding practice on nutritional status of under-five children. Indian Journal of Pediatrics. 2006; 73:417422.

17. Mengistu K, Alemu K, Destaw B. Prevalence of malnutrition and associated factors among children aged 6-59 months at Hidabu Abote district, North Shewa, Oromia regional state. Nutritional Disorders \& Therapy 2013; T1: 001. doi:10.4172/2161-0509.T1-001. 
18. UNICEF. Tracking Progress on Child and Maternal Nutritional survival and development priority, 2010.

19. Khan MMH, Krämer A, KhandokePrüfer-Krämer L, Islam A. Trends i 42 demographic and health-related indican Bangladesh, 1993-2007: will inequities persist? Bull World Health Organ. 2011; 89:583-593

20. de Onis M, Brown D, Blössner M, Borghi E: Levels and trends in child malnutrition: UNICEF-WHO-The World Bank joint child malnutrition estimates, 2012. ISBN 978924 1504515.

21. Islam MM, Alam M, Tariquzaman M, Kabir MA, Pervin R, Begum M, Khan MMH. Predictors of the number of under-five malnourished children in Bangladesh: application of the generalized Poisson regression model. BMC Public Health 2013; 13:11.

22. Mancharia CW, Kog-Makau W, Murok NM .Dietary intake, feeding and care practices at children in Kathonzweni, Division, Makuenl, district, Kenya. East Africa Medical journal. 2004; 81: 5-6.

23. Mondal MNI, Nazrul HM, Chowdhury MRK, Howard J. Socio-demographic factors affecting knowledge level of Tuberculosis patients in Rajshahi City, Bangladesh. African Health Sciences 2014; 14(4):855865. DOI: http://dx.doi.org/10.4314/ahs.v14i4.13

24. Haque SE, Rahman M, Mostofa MG, Zahan MS. Reproductive health care utilization among young mothers in Bangladesh: Does autonomy matter? Women's Health Issues. 2011; 22(2):e171-80.

25. Franz J. Improving nutrition: Early childhood development and mobile health. Impact and Innovation Series. The National Bureau of Asian Research; 2012, http://www.pacifichealthsummit.org/downlo ads/Impact\%20\&\%20Innovations/Improvin g_Nutrition.PDF . (Accessed on 1 July 2019)

26. United Nations Development Programme (UNDP). Human Development Report, 2005. International cooperation at a crossroads. Aid, trade and security in an unequal world. ISBN 0-19-530511-6

27. BDH (Bangladesh Demographic and Health) Survey, 2011. National Institute of Population Research and Training (NIPORT) Mitra and Associates \& Macro International. Dhaka, Bangladesh and Calverton, Maryland, USA; 2013.

28. Kabir I, Khanam M, Agho KE, Mihrshahi S, Dibley MJ, Roy SK. Determinants of inappropriate complementary feeding practices in infant and young children in Bangladesh: secondary data analysis of Demographic Health Survey 2007. Maternal and Child Nutrition 2012; 8 (Suppl. 1), pp. 11-27.

29. Patel A, Pusdekar Y, Badhoniya N, Borkar J, Agho KE, Dibley MJ. Determinants of inappropriate complementary feeding practices in young children in India: secondary analysis of National Family Health Survey 2005-2006. Maternal and Child Nutrition 2012, 8 (Suppl. 1): pp. 28-44

30. Hazir T, Senarath U, Agho K, Akram DS, Kazmi N, Abbasi S, Dibley MJ. Determinants of inappropriate timing of introducing solid, semi-solid or soft food to infants in Pakistan: Secondary data analysis of Demographic and Health Survey 20062007. Maternal and Child Nutrition 2012; 8(1): 78-88.

31. Wamani H, Astrom AN, Peterson S, Tylleska T, Tumwine JK. Infant and Young Child Feeding in Western Uganda: Knowledge, Practices and Socio-economic Correlates. 
Journal of Tropical Pediatrics 2005; 51(6): 356-361.

32. Patel A, Pusdekar Y, Badhoniya N, Borkar J, Agho KE, Dibley MJ. Determinants of inappropriate complementary feeding practices in young children in India: secondary analysis of National Family Health Survey 2005-2006. Maternal and Child Nutrition 2012; 8(1): 28-44.

33. Charmaine SN, Dibley MJ, Aghe Complementary feeding indicator. 43 determinants of poor feeding practices in Indonesia: a secondary analysis of 2007 Demographic and Health Survey data. Public Health Nutrition 2011; 15(5), 827-839.

34. Khanal V, Sauer K, Zhao Y. Determinants of complementary feeding practices among Nepalese children aged 6-23 months: findings from demographic and health survey 2011. BMC Pediatrics 2013; 13:131.

35. Sharma A, Kader M. Effect of women's decision-making autonomy on infant's birth weight in rural Bangladesh. ISRN Pediatrics 2013.

36. Henry FJ, Briend A, Fauveau V, Huttly SA, Yunus M, Chakraborty J. Gender and age differentials in risk factors for childhood malnutrition in Bangladesh. Ann Epidemiol. 1993; 3:382-6.

37. Liubai LI, Sujun LI, Ali M, Ushijima H. Feeding practice of infants and their correlates in urban areas of Beijing, China. Pediatrics International 2003; 45: 400-406.

38. Garg A, Chadha R. Index for Measuring the Quality of Complementary Feeding Practices in Rural India. J Health Popul Nutr 2009; 27(6):763-771

39. Faber M, Benade AJS. Nutritional status and dietary practices of 4-24-month-old children from a rural South African community. Public Health Nutrition 1998; 2(2), 179-185.

\section{Author contributions : 1st author Naznin Pervin} was involved in concept and design of the paper; $2^{\text {nd }}$ and $3^{\text {rd }}$ authors Darryl Macer and Shamima P. Lasker were equally involved in the literature search, review, compilation, manuscript writing and revision respectively.

Conflict of interest : There is no conflict of interest relevant to this paper to disclose 
Bangladesh Journal of Bioethics 2018; 9 (3): 28-44 